\title{
RETRACTED ARTICLE: Can baseline endocrinological examination and thyroid ultrasound predict the development of thyroid disease in immunotherapy-treated patients? Results from a prospective, single-center, open-label study
}

\author{
Stefano Gay ${ }^{1} \cdot$ Giovanni Rossi $^{2}$ - Giuliana Corica ${ }^{1} \cdot$ Giulia Graziani $^{1}$ - Carlo Genova ${ }^{2}$ - Erika Rijavec ${ }^{2}$. \\ Marco Tagliamento ${ }^{2} \cdot$ Francesco Grossi $^{3} \cdot$ Massimo Giusti ${ }^{1}$
}

Received: 30 October 2018 / Accepted: 24 January 2019 / Published online: 6 March 2019

(c) Springer Science+Business Media, LLC, part of Springer Nature 2019

The authors are retracting this article [1] because they do not have permission to publish the data from the study reported. As the data are confidential, the content of this article has been removed from the journal website. All authors agree with this retraction.

\section{References}

1. S. Gay, G. Rossi, G. Corica, G. Graziani, C. Genova, E. Rijavec, M. Tagliamento, F. Grossi, M. Giusti, Can baseline endocrinological examination and thyroid ultrasound predict the development of thyroid disease in immunotherapy-treated patients? Endocrine (2019). https://doi.org/10.1007/s12020-019-01854-8
Stefano Gay

stefano.gay89@gmail.com

Endocrine Unit, Ospedale Policlinico San Martino, Genoa, Italy

Lung Cancer Unit, Ospedale Policlinico San Martino, Genoa, Italy

3 Oncology Unit, Ospedale Policlinico Maggiore, Milan, Italy 